Research Article

\section{The Renin-Angiotensin System:}

\section{Alamandine is reduced in patients with Idiopathic Pulmonary Fibrosis}

\author{
Taís Salvi Sipriani ${ }^{1}$, Robson Augusto Souza dos Santos ${ }^{2}$ and \\ Katya Rigatto ${ }^{1 *}$ \\ 'Laboratório de Fisiologia Translacional, Curso de Pós-Graduação em Ciências da Saúde, \\ Universidade Federal de Ciências da Saúde de Porto Alegre, RS, Brazil \\ 'Laboratório de Hipertensão, Departamento de Fisiologia e Biofísica, Instituto de Ciências \\ Biológicas, Universidade Federal de Minas Gerais, Belo Horizonte, MG, Brazil
}

\section{Abstract}

Idiopathic Pulmonary Fibrosis (IPF) is a chronic and progressive disease without treatment that leads to death. Therefore, to control its progression to pulmonary hypertension is still a challenge. Moreover, there is no study that has investigated the Renin-Angiotensin System in patients with IPF.

Objective: Verify the plasma concentrations of Angiotensin I, Angiotensin II (Angll), Angiotensin-(1-7) [Ang- (1-7)] and Alamandine in patients with IPF.

Methods: Ten IPF patients, with or without $\mathrm{PH}$, were included, and ten controls matched by sex and age. Quantitative plasma peptide concentrations (PPC) were expressed as mean and standard deviation or median and interquartile range. The Student Newman-Keuls t test was used for parametric data, Mann-Whitney for nonparametric data and, to compare proportions, the Fisher exact test was performed. The associations between clinical variables and the PPC were evaluated by Pearson or Spearman correlation coefficients. A $p \leq 0.05$ was considered statistically significant.

Results: The Alamandine plasma concentration was significantly (365\%) lower in the IPF group and positively associated $(r=0.876)$ with pulmonary artery pressure (PAP). In addition, only in control group, the forced expiratory volume (FEV1\%) was positively associated $(p=0.758)$ with Ang-(1-7).

Conclusion: This study showed, for the first time, that there is a decrease in Alamandine participation in patients with IPF. The ACE-Angll-AT1 axis may be more active in this disease. In addition, our results suggest that Alamandine might be compensating the increase in PAP, as well as the Ang-(1-7) is improving the forced expiratory volume.

\section{More Information}

*Address for Correspondence: Katya Rigatto, Av Sarmento Leite, 245-Prédio 3, Laboratório 503, CEP: 90050-170; Tel: 55 (51) 99998-6655; Email:krigatto@gmail.com

Submitted: 06 September 2019

Approved: 19 November 2019

Published: 20 November 2019

How to cite this article: Sipriani TS, dos Santos RAS, Rigatto K. The Renin-Angiotensin System: Alamandine is reduced in patients with Idiopathic Pulmonary Fibrosis. J Cardiol Cardiovasc Med. 2019; 4: 210-215.

DOI: dx.doi.org/10.29328/journal.jccm. 1001070

Copyright: @ 2019 Sipriani TS, et al. This is an open access article distributed under the Creative Commons Attribution License, which permits unrestricted use, distribution, and reproduction in any medium, provided the original work is properly cited.

Keywords: Idiopathic-Pulmonary-Fibrosis; Alamandine; Renin-Angiotensin System

D) Check for updates

\section{Introduction}

Idiopathic Pulmonary Fibrosis (IPF) is more prevalent in males [1,2] than females and it is characterized by progressive scarring of lung tissue [3]. It is considered the most severe form of pulmonary fibrosis, without treatment and after diagnosis, the survival is around three years [4].

Although its etiology remains unknown, it is established that IPF is associated with aging, collagen deposition, fibroblast proliferation and excessive accumulation of extracellular matrix [5]. In addition, pulmonary hypertension
$(\mathrm{PH})$ is a common complication in IPF [6] and its treatment also remains elusive [7]. Thus, the understanding of IPF physiopathology, as well as to slow or even control the onset of PH, could improve the quality of life and also the survival of these patients.

Results from studies in animals [8,9] and human lung tissue $[8,10]$ demonstrated that the renin angiotensin system (RAS) plays an important role in lung fibrosis. It has been demonstrated that angiotensin II (AngII) is involved in the fibrosis promotion [11]. Thus, considering this involvement, and the importance of ACE-AngII-AT ${ }_{1}$ axis to provoke 
vasoconstriction, cell migration, proliferation [12,13] and fibrosis [11], and mainly considering that the lungs are an important site of AngII formation, our objective was to study the participation of this system in IPF.

Angiotensin I (AngI), converted into AngII by angiotensin converting enzyme (ACE), can also be cleaved by angiotensin converting enzyme II (ACE2) to form Ang(1-7) [14]. In addition, the imbalance between ACE-AngII-AT ${ }_{1}$ and ACE2Ang-(1-7)-Mas plays an important role in the pathogenesis of many diseases $[15,16]$ including fibrotic disorders $[8,17,18]$. Collectively, these findings demonstrate the importance to keep the balance in favor to the ACE2-Ang-(1-7)-Mas axis.

In fact, studies $[17,18]$ have shown that ACE2Ang-(1-7)Mas axis may have a role in pulmonary fibrosis [8] found in mice that ACE2 inhibition induced an increase in tissue expression of AngII and provoked pulmonary fibrosis [8], indicating that ACE2-Ang-(1-7)-Mas axis might, at least, reduce the fibrosis progression. Therefore, it is reasonable to believe that the imbalance between the ACE-AngII-AT ${ }_{1} /$ ACE2-Ang-(1-7)-Mas axes may significantly participate in the physiopathology of IPF.

To make the challenge even more interesting, the recent discovery of a new component of this system, Alamandine [19], has further enriched the role of RAS in this disease. It is known that Alamandine, formed either from the decarboxylation of Ang- (1-7) or from Angiotensin A by ACE2 [20] and acting through the MrgD receptor, has antifibrotic and antihypertensive effects, reduces collagen I, III and fibronectin accumulation in mice with cardiac fibrosis [19].

On the other hand, despite of all those evidences, there are no studies focused on the role of RAS in the physiopathology of IPF. Numerous studies have shown that in the disease ACE-AngII-AT ${ }_{1}$ axis is overactive, but there is no study in the literature focused in the balance between axes. Moreover, to the moment, all treatments are focused only on blocking the ACE-AngII-AT 1 axis and did not taking into account the importance of the counter-regulatory axis. Possibly the ratio between ACE2-Ang-(1-7)Mas axis and/or ACE2-AlamandineMrgD versus ACE-AngII-AT ${ }_{1}$ is unbalanced and this could facilitate the disease progression. Although having opposite effects, the importance of the balance between these axes has been underestimated, emphasizing the importance of more studies in this direction. It is possible that, more important than exclusively block the ACE-AngII-AT ${ }_{1}$ axis, to stimulate the ACE2-Ang-(1-7)-Mas and/or ACE2-Alamandine-MrgD axes, could improve the efficiency of the diseases treatment.

Thus, our goal is to provide more information about RAS participation in IPF and to draw the attention to the importance of this balance. In the future, we intend to have contributed to improve the quality of life and survival of IPF patients.

\section{Methods}

The study was performed according to the standard established by the Declaration of Helsinki. The Ethics Committee of the Irmandade Santa Casa de Misericórdia de Porto Alegre (ISCMPA), Rio Grande do Sul, Brazil, approved the project (number 1293420) and all subjects agreed to participate and signed a consent form.

\section{Participants}

This study used a cross-sectional convenience patient sample recruited from the ISCMPA.

The study enrolled patients with IPF $(n=10)$, diagnosed by lung biopsy. All patients were evaluated for weight, height, body mass index (BMI), blood pressure, medications and previous illness. Seven patients performed spirometry test and all patients were submitted to the six-minute walk test, according to the guidelines of the American Thoracic Society [21]. In addition, the pulmonary artery pressure was measured only in five patients because two had no indication. The control group $(n=10)$ consisted of healthy age and gender matched. The health status was determined through anamnesis and all individuals self-declared without disease.

Smokers, alcohol users or with neurological and/or musculoskeletal disorders were excluded. Moreover subjects/ patients with heart or kidney failure taking antibiotics, ACE inhibitors, beta-blockers or any drug that would interfere with the renin angiotensin system were excluded of the study. The other medications used by the patients had no evidences that could influence the parameters analyzed in this study.

\section{Study protocol}

The study was conducted in patients with IPF from ISCMPA. Circulating concentration of RAS peptides were measured in both groups.

The evaluation of circulating RAS: after a fasting period of 12 hours and a 5 minutes resting in the laboratory, blood was collected $(5 \mathrm{ml})$ by a trained professional through peripheral venipuncture.

\section{Blood collection and plasma extraction}

The five milliliters of blood were stored in a BD Vacuette ${ }^{\circledR}$ EDTA tube containing a protease inhibitor cocktail (Complete $^{\mathrm{TM}}$, Mini-Protease Inhibitor Cocktail Tablets, Roche $^{\circledR}$-Germany) prepared according to the manufacturer's instructions.

The blood was centrifuged for 10 minutes, 3,500 rpm at $4^{\circ} \mathrm{C}$. The plasma was separated and frozen at $-80^{\circ} \mathrm{C}$ to measure AngI, AngII, Ang-(1-7) and Alamandine.

\section{Peptides measurements}

A reversed-phase high performanceliquid chromatography 
coupled to electrospray ionization tandem mass spectrometry (LC-ESI-MS-MS) was developed for Angiotensin I, Angiotensin II, Angiotensin-(1-7) and Alamandine determination in human plasma. The procedure for extraction involved a solidphase analytical method. Ten $\mu$ of the extraction solution was injected in the system. The chromatography separation was performed with an ACQUITY UPLC BEH C18 Column, $1.7 \mu \mathrm{m}$, $2.1 \mathrm{~mm}$ X $100 \mathrm{~mm}$ Waters (Milford, MA, Ireland).

Detection was in MRM mode, using an electrospray positive ionization. The ion transition monitored was $(\mathrm{m} / \mathrm{z}: \quad(433.2>647.4) \rightarrow(349.7>371.2), \quad(300.7>371.2)$ and $(286>327.2)$ for Angiotensin I, Angiotensin II, Angiotensin-(1-7) and Alamandine, respectively.

The calibration curve was prepared using a stock solution mixture with all the synthetic standards (Bachem Inc., Torrance, CA). The applied calibration curve model $y=a x+b$ proved to be accurate over the concentration range 0,05-1 $\mathrm{ng} / \mathrm{mL}$, with a correlation coefficient of 0.99 . The inter- and intra-assay variability was $\leq 15 \%$. The sensitivity of the assay was in the lower picogram range (2-10 pg/sample).

\section{Statistics}

The qualitative variables were described by absolute and relative frequencies. Student's t test was used to compare means between groups. The data were submitted to a normality test and, when the asymmetry was verified, the statistical Mann-Whitney test was performed.

The Fisher exact test was used to compare proportions and Pearson or Spearman correlation coefficients were used to detect associations.

Quantitative variables were expressed as mean and standard deviation or median and interquartile range. When $p \leq 0.05$ the data were considered statistically different.

All analyzes were performed using SPSS version 21.

\section{Results}

The weight and body mass index (BMI) were significantly different between groups (Table 1). On the other hand, regarding to age, sex, height, as well as the hemodynamic data such as systolic blood pressure (SBP) and diastolic blood pressure (DBP) there were no difference between groups.

There was a significant difference between groups regarding the spirometry variables and the distance covered in the six minutes' walk test (6MWT-Table 2).

The plasma concentration of AngI, AngII and Ang-(1-7) was not different between groups but the IPF group showed a significant reduction in the Alamandine plasma concentration of (Table 3). The power of Alamandine result was $100 \%$ (StataCorp. 2017. Stata Statistical Software: Release 15. College Station, TX: StataCorp LLC), and the effect size was 4.30 at $95 \%$ of confidence coefficient.
There was also a positive correlation between of this concentration with pulmonary artery pressure (PAP). The control group demonstrated a positive correlation between forced expiratory volume in one second $\left(\mathrm{FEV}_{1}\right)$ with Ang- (17) (Table 4).

\begin{tabular}{|c|c|c|c|}
\hline \multicolumn{4}{|l|}{ Table 1: Sample characterization. } \\
\hline Variables & Control $(\boldsymbol{n}=\mathbf{1 0})$ & IPF $(\boldsymbol{n}=\mathbf{1 0})$ & $\boldsymbol{p}$ \\
\hline Age (years) & $58 \pm 13$ & $58 \pm 13$ & 0.973 \\
\hline Male & 6 & 6 & 1.000 \\
\hline White ethnicity & 10 & 8 & 0.474 \\
\hline Weight $(\mathrm{kg})$ & $80 \pm 13$ & $67 \pm 9.4$ & 0.023 \\
\hline Height $(\mathrm{m})$ & $1.68 \pm 0.10$ & $1.63 \pm 0.08$ & 0.299 \\
\hline BMI $\left(\mathrm{kg} / \mathrm{m}^{2}\right)$ & $28 \pm 4$ & $25 \pm 1.9$ & 0.041 \\
\hline
\end{tabular}

Values expressed as mean \pm standard deviation; IPF: Idiopathic Pulmonary Fibrosis: BMI: Body Mass Index.

\begin{tabular}{|c|c|c|c|}
\hline Variables & Control & IPF & $p$ \\
\hline $\mathrm{FVC}(\mathrm{ml})^{\mathrm{a}}$ & $3.6 \pm 0.64$ & $1.9 \pm 0.69$ & 0.000 \\
\hline FVC $(\%)^{a}$ & $89 \pm 8.5$ & $56 \pm 22$ & 0.000 \\
\hline $\mathrm{FEV}_{1}(\mathrm{ml})^{\mathrm{a}}$ & $3 \pm 0.51$ & $3.05 \pm 3.45$ & 0.000 \\
\hline $\operatorname{FEV}_{1}(\%)^{a}$ & $91.3 \pm 8$ & $58 \pm 19$ & 0.000 \\
\hline $\mathrm{FEV}_{1} / \mathrm{FVC}$ & $0.82 \pm 0.06$ & $88.5 \pm 4.0$ & 0.524 \\
\hline PAP $(\mathrm{mmHg})$ & - & $50 \pm 13$ & - \\
\hline Diagnostic time (years) & - & $2.15 \pm 1.45$ & - \\
\hline Oxygen Use & - & 6 & - \\
\hline Distance in 6MWT $(\mathrm{m})$ & $558.87 \pm 61.38$ & $421 \pm 171$ & 0.03 \\
\hline Distance in 6MWT (\%) & $95.81 \pm 6.84$ & $74 \pm 31$ & 0.02 \\
\hline
\end{tabular}

apulmonary function tests pre-bronchodilator; FVC: Forced Vital Capacity; FEV Forced Expiratory Volume in one second; FEV /FVC ratio: Tiffeneau-Pinelli index (IPF and Control, $n=7$ ); PAP: Pulmonary Artery Pressure (IPF, $n=5) ; 6 \mathrm{MWT}(\mathrm{m} ; \%)$ : Distance covered in the walk test of six minutes in meters and percentage (IPF, $n=$ 10 and control, $n=8)$. Values expressed as mean \pm standard deviation.

Table 3: Renin-Angiotensin-System peptides plasma concentration $(\mathrm{pg} / \mathrm{mL})$.

\begin{tabular}{|c|c|c|c|}
\hline Variables & Control $(\boldsymbol{n}=\mathbf{1 0})$ & IPF $(\boldsymbol{n}=10)$ & $\boldsymbol{p}$ \\
\hline Angiotensin I & $22(16.6-33.4)$ & $37(22.9-81.9)$ & 0.089 \\
\hline Angiotensin II & $7.78(4.95-15.6)$ & $9.84(4.56-20.4)$ & 0.780 \\
\hline Angiotensin-(1-7) & $31(20.5-36.3)$ & $28(25.8-34.6)$ & 0.684 \\
\hline Alamandine & $2,7 \pm 0,47$ & $0,74 \pm 0,44$ & 0.0001 \\
\hline
\end{tabular}

Alamandine plasma concentration is expressed as mean \pm standard deviation. The other values are presented as median.

Table 4: Associations between clinical variables and Renin-Angiotensin-System peptides.

\begin{tabular}{|c|c|c|c|c|}
\hline Variables & Angl & Angll & Ang-(1-7) & Alamandine \\
\hline \multicolumn{5}{|l|}{ Patients } \\
\hline $\mathrm{FVC}(\mathrm{mL})$ & $r=-0.084$ & $r=0.050$ & $r=0.105$ & $r=-0.115$ \\
\hline FVC (\%) & $r_{s}=-0.042$ & $r_{s}=-0.134$ & $r_{\mathrm{s}}=-0.393$ & $r=0.106$ \\
\hline $\mathrm{FEV}_{1}(\mathrm{~mL})$ & $r=-0.064$ & $r=0.015$ & $r=0.087$ & $r=-0.027$ \\
\hline $\mathrm{FEV}_{1}(\%)$ & $r_{\mathrm{s}}=-0.059$ & $r_{\mathrm{s}}=-0.176$ & $r_{\mathrm{s}}=-0.427$ & $r=0.115$ \\
\hline $\mathrm{FEV}_{1} / \mathrm{FVC}$ & $r=-0.032$ & $r=0.224$ & $r=-0.021$ & $r=0.325$ \\
\hline $\mathrm{PAP}(\mathrm{mmHg})$ & $r_{\mathrm{s}}=0.400$ & $r_{\mathrm{s}}=0.000$ & $r_{\mathrm{s}}=-0.200$ & $r=0.876^{\star}$ \\
\hline Diagnostic time (years) & $r_{\mathrm{s}}=0.217$ & $r_{\mathrm{s}}=0.093$ & $r_{\mathrm{s}}=0.093$ & $r_{\mathrm{s}}=0.106$ \\
\hline Distance in 6MWT (\%) controls & $r_{\mathrm{s}}=-0.333$ & $r_{\mathrm{s}}=-0.236$ & $r_{\mathrm{s}}=-0.018$ & $r=-0.249$ \\
\hline $\begin{array}{l}\text { FVC }(\mathrm{mL}) \\
\mathrm{FVC}(\%) \\
\mathrm{FEV}_{1}(\mathrm{~mL})\end{array}$ & $\begin{array}{l}r=0.434 \\
r=0.280 \\
r=0.537\end{array}$ & $\begin{array}{l}r=-0.027 \\
r=0.236 \\
r=-0.138\end{array}$ & $\begin{array}{l}r=0.084 \\
r=0.462 \\
r=0.312\end{array}$ & $\begin{array}{l}r=-0.227 \\
r=0.259 \\
r=-0.056\end{array}$ \\
\hline $\begin{array}{c}\mathrm{FEV}_{1}(\%) \\
\mathrm{FEV}_{1} / \mathrm{FVC}\end{array}$ & $\begin{array}{l}r=0.343 \\
r=0.168\end{array}$ & $\begin{array}{l}r=-0.118 \\
r=-0.316\end{array}$ & $\begin{array}{c}r=0.759 \star \star \\
r=0.508\end{array}$ & $\begin{array}{l}r=0.523 \\
r=0.398\end{array}$ \\
\hline Distance in 6MWT (m) & $r=-0.107$ & $r=-0.179$ & $r=-0.227$ & $r=-0.133$ \\
\hline Distance in 6MWT (\%) & $r=-0.561$ & $r=-0.287$ & $r=-0.471$ & $r=0.05$ \\
\hline
\end{tabular}

FVC: Forced Vital Capacity; FEV : Forced Expiratory Volume in one second;

$\mathrm{FEV}_{1} / \mathrm{FVC}$ ratio: Tiffeneau-Pinelli index $(n=7)$; PAP: Pulmonary Artery Pressure $(n=5) ; 6 \mathrm{MWT}(\mathrm{m} ; \%)$ : Distance covered in the walk test of six minutes in meters and percentage (IPF, $n=10$ and control, $n=8$ ). Amounts in Pearson correlation coefficients (r) and Spearman (rs). ${ }^{\star} p: 0.124 ;{ }^{\star \star} p: 0.02$. 


\section{Discussion}

The most important observation of this study was that patients with IPF showed a significant decrease in Alamandine plasmatic concentrations, while AngI, AngII and Ang-(1-7) were similar to controls. In addition, there was also a positive association of Alamandine concentration with the pulmonary artery pressure and, in control group, between forced expiratory volume $\left(\mathrm{FEV}_{1} \%\right)$ and Ang-(1-7) plasma concentration.

Our results showed that body weight and BMI of IPFpatients were significantly lower than controls. These results are probably due to the higher metabolic expenditure frequently seen in the IPF-patients. In fact, these results agree with those found by Alakhras, et al. [22], who demonstrated that the majority of IPF patients present a BMI and weight within or above the normal range [22]. In fact, it would be expected that patients with pulmonary diseases had a decrease in body weight due to hypoxemia found when there is a respiratory injury. According to Bunn \& Poyton [23], the hypoxemia modifies the muscles by generating a sharp decline in protein synthesis to adapt the oxygen supply to the respiratory demand in these patients [23]. Weight loss is also a serious problem in patients with cystic fibrosis [24,25].

These clinical signs probably exasperate the loss of muscle mass through oxidative stress and inflammatory responses [26].

As expected, there was also a significant difference between the groups regarding to the spirometry variables and to the results found in the six-minute walk test. These findings demonstrate the clinical difference between groups, one with serious health problem compared to a healthy one.

On the other hand, although in vivo studies have shown that AngII plays an important role in lung fibrogenesis [11] and that there is an increase in this peptide in pathological situations associated to fibrosis [27-29], our results showed that Angl, AngII and Ang(1-7) plasma concentration were not different between groups. This apparently unexpected finding remains to be explained, particularly regarding to AngII plasma concentration that it is similar in PIF- patients and controls. A possible explanation could be related to the fact that was have measured in the plasma and in the majority of the data from the literature the AngII measurements are from tissues and also from different species. It is also possible that, in human being, the balance between the two axes is more important than their absolute values. In addition, the literature has shown that the uses of ACE inhibitors attenuate experimental pulmonary fibrosis [9,30-32]. It is important to consider that the ACE inhibition could be changing this balance. This was the reason why the subjects who were taking ACE inhibitor or beta-blockers were excluded from our study.

Moreover, Jiang, et al. [33] demonstrated in a mouse model of Alzheimer's disease that there was a significant decrease in plasma concentrations of Ang-(1-7), indicating that the decrease in this peptide is associated to a degenerative pathology. We did not find a significant difference in Ang(1-7) plasma concentration between groups, but we did find in Alamandine plasma concentration. It is known that Alamandine can be formed from Ang-(1-7) decarboxylation [34]. In our study, the IPF-patients had 356\% less Alamandine than controls, which could be an indication that also Ang(1-7) was decreased or, that there was a preference to keep the plasma concentration of Ang-(1-7). Another possible explanation could be the fact that the balance among peptides plasma and/or tissue concentrations is more important than the absolute values of each alone. The predominance of one, and its respective actions, could be important to counteract the detrimental effects of a disease.

Although Lautner, et al. [19], showed an increase in plasma concentration of Alamandine in nephropathic patients, it is important to consider the known anti-fibrotic effect of this peptide [19]. It would be reasonable that patients with IPF showed a reduction in Alamandine plasma concentration. Nephropathic patients present hemodynamic changes that could justify the need for vasodilation to offset the reduction in renal filtration. Accordingly, the increased Alamandine could be promoting vasodilation to compensate the volume overload, counteracting that effect.

In contrast, our results did show in patients a positive association between Alamandine plasma concentration and PAP. This result indicates that Alamandine could be attempting to minimize the effects on pulmonary artery pressure. In fact, our study was the first to demonstrate in patients with IPF that Alamandine plasma concentrations is decreased, and positively associated to PAP. In addition, there was a positive associated between $\mathrm{FEV}_{1}(\%)$ and Ang-(1-7) in the control group. This could be due to a favorable effect of Ang-(1-7) over thoracic chamber expansion/retraction in healthy subjects.

We do believe that our findings can contribute to better understand the pathology of IPF. Both Ang-(1-7) and Alamandine may represent a new counter-regulatory axis to the deleterious effects of AngII [35]. Our primary goal was to study the balance between the final peptides of the two RAS axes. It was a particular goal to, for the first time, demonstrate that there is a significant difference in Alamandine plasma concentrationan between healthy and IPF patients. On the other hand, it would be very interesting also to show the RAS involvement with the lung tissue injury, and the participation of Angiontensin A and Aldosterone plasmatic concentration in IPF. The Angiotensin A is an important peptide for the Alamandine formation and aldosterone is also involved in the fibrosis process. Future investigation in experimental models and humans might clarify the participation of both axes of RAS in IPF. Thus, the scientific community will be closer to develop an effective treatment to this disease. 
This study suggest, for the first time, that there is a decrease in Alamandine participation in patients with IPF, indicating that ACE-AngII-AT1 axis may be proportionally more active in this disease.

The authors declare that there are no conflicts of interest in the conception of this study.

\section{Author Contributions}

The experiments were carried out in the Laboratório de Fisiologia Translacional da Universidade Federal de Ciências da Saúde de Porto Alegre, Brazil and in the Laboratório de Hipertensão da Universidade Federal de Minas Gerais, Belo Horizonte, Brazil.

We declare that all authors have approved the final version of the manuscript and agree to be accountable for all aspects of the manuscript.

\section{Financing}

This work was supported by Conselho Nacional de Desenvolvimento Científico e Tecnológico (CNPq).

\section{Acknowledgment}

We thank the entire pulmonary rehabilitation team at ISCMPA and the hypertension laboratory for the support and assistance in completing this study.

\section{References}

1. Navaratnam V, Fleming KM, West J, Smith CJ, Jenkins RG, et al. The rising incidence of idiopathic pulmonary fibrosis in the U.K. Thorax. 2011; 66: 462-467.

PubMed: https://www.ncbi.nlm.nih.gov/pubmed/21525528

2. Raghu G, Weycker D, Edelsberg J, Bradford WZ, Oster G. Incidence and prevalence of idiopathic pulmonary fibrosis. Am J Respir Crit Care Med. 2006; 174: 810-816.

PubMed: https://www.ncbi.nlm.nih.gov/pubmed/16809633

3. Selman M, King TE, Pardo A; American Thoracic Society; European Respiratory Society, et al. Idiopathic pulmonary fibrosis: prevailing and evolving hypotheses about its pathogenesis and implications for therapy. Ann Intern Med. 2001; 134: 136-151.

PubMed: https://www.ncbi.nlm.nih.gov/pubmed/11177318

4. Yan Z, Kui Z, Ping Z. Reviews and prospectives of signaling pathway analysis in idiopathic pulmonary fibrosis. Autoimmun Rev. 2014; 13 1020-1025.

PubMed: https://www.ncbi.nlm.nih.gov/pubmed/25182202

5. Raghu G, Collard HR, Egan JJ, Martinez FJ, Behr J, et al. An official ATS/ERS/JRS/ALAT statement: idiopathic pulmonary fibrosis: evidence-based guidelines for diagnosis and management. Am J Respir Crit Care Med. 2011; 183: 788-824.

PubMed: https://www.ncbi.nlm.nih.gov/pubmed/21471066

6. Lettieri CJ, Nathan SD, Barnett SD, Ahmad S, Shorr AF. Prevalence and outcomes of pulmonary arterial hypertension in advanced idiopathic pulmonary fibrosis. Chest. 2006; 129: 746-752.

PubMed: https://www.ncbi.nlm.nih.gov/pubmed/16537877

7. Woodcock HV, Maher TM. The treatment of idiopathic pulmonary fibrosis. F1000Prime Rep. 2014; 6: 16.

PubMed: https://www.ncbi.nlm.nih.gov/pubmed/24669297
8. Li X, Molina-Molina M, Abdul-Hafez A, Uhal V, Xaubet $A$, et al Angiotensin converting enzyme-2 is protective but downregulated in human and experimental lung fibrosis. Am J Physiol Lung Cell Mol Physiol. 2008; 295: L178-185.

PubMed: https://www.ncbi.nlm.nih.gov/pubmed/18441099

9. Molteni A, Wolfe LF, Ward WF, Ts'ao CH, Molteni LB, et al. Effect of an angiotensin II receptor blocker and two angiotensin converting enzyme inhibitors on transforming growth factor-beta (TGF-beta) and alphaactomyosin (alpha SMA), important mediators of radiation-induced pneumopathy and lung fibrosis. Curr Pharm Des. 2007; 13: 1307-1316. PubMed: https://www.ncbi.nlm.nih.gov/pubmed/17506716

10. Uhal BD, Kim JK, Li X, Molina-Molina M. Angiotensin-TGF-beta 1 crosstalk in human idiopathic pulmonary fibrosis: autocrine mechanisms in myofibroblasts and macrophages. Curr Pharm Des. 2007; 13: 1247-1256

PubMed: https://www.ncbi.nlm.nih.gov/pubmed/17504233

11. Uhal BD, Li X, Piasecki CC, Molina-Molina M. Angiotensin signalling in pulmonary fibrosis. Int $\mathrm{J}$ Biochem Cell Biol. 2012; 44: 465-468. PubMed: https://www.ncbi.nlm.nih.gov/pubmed/22155301

12. Kim S, Iwao H. Molecular and cellular mechanisms of angiotensin IImediated cardiovascular and renal diseases. Pharmacol Rev. 2000; 52: 11-34.

PubMed: https://www.ncbi.nlm.nih.gov/pubmed/10699153

13. Mehta PK, Griendling KK. Angiotensin II cell signaling: physiological and pathological effects in the cardiovascular system. Am J Physiol Cell Physiol. 2007; 292: C82-97.

PubMed: https://www.ncbi.nlm.nih.gov/pubmed/16870827

14. Ferrario CM, Chappell MC, Tallant EA, Brosnihan KB, Diz DI. Counterregulatory actions of angiotensin-(1-7). Hypertension. 1997; 30: 535541.

PubMed: https://www.ncbi.nlm.nih.gov/pubmed/9322978

15. Santos RA, Simoes e Silva AC, Maric C, Silva DM, Machado RP, et al Angiotensin-(1-7) is an endogenous ligand for the $G$ protein-coupled receptor Mas. Proc Natl Acad Sci U S A. 2003; 100: 8258-8263. PubMed: https://www.ncbi.nlm.nih.gov/pubmed/12829792

16. Tallant EA, Ferrario CM, Gallagher PE. Angiotensin-(1-7) inhibits growth of cardiac myocytes through activation of the mas receptor. Am J Physiol Heart Circ Physiol. 2005; 289: H1560-1566. PubMed: https://www.ncbi.nlm.nih.gov/pubmed/15951342

17. Shenoy V, Ferreira AJ, Qi Y, Fraga-Silva RA, Díez-Freire C, et al. The angiotensin-converting enzyme 2/angiogenesis-(17)/Mas axis confers cardiopulmonary protection against lung fibrosis and pulmonary hypertension. Am J Respir Crit Care Med. 2010; 182: 1065-1072. PubMed: https://www.ncbi.nlm.nih.gov/pubmed/20581171

18. Uhal BD, Li X, Xue A, Gao X, Abdul-Hafez A. Regulation of alveolar epithelial cell survival by the ACE-2/angiotensin 1-7/Mas axis. Am J Physiol Lung Cell Mol Physiol. 2011; 301: L269-274.

PubMed: https://www.ncbi.nlm.nih.gov/pubmed/21665960

19. Lautner RQ, Villela DC, Fraga-Silva RA, Silva N, Verano-Braga T, et al Discovery and characterization of alamandine: a novel component of the renin-angiotensin system. Circ Res. 2013; 112: 1104-1111. PubMed: https://www.ncbi.nlm.nih.gov/pubmed/23446738

20. Mendoza-Torres E, Oyarzún A, Mondaca-Ruff D, Azocar A, Castro PF, et al. ACE2 and vasoactive peptides: novel players in cardiovascular/renal remodeling and hypertension. TherAdv Cardiovasc Dis. 2015; 9:217-237. PubMed: https://www.ncbi.nlm.nih.gov/pubmed/26275770

21. ATS statement: guidelines for the sixminute walk test. ATS statement guidelines for the six-minute walk test. Am J Respir Crit Care Med. 2002; 166: 111-117.

PubMed: https://www.ncbi.nlm.nih.gov/pubmed/12091180 
22. Alakhras M, Decker PA, Nadrous HF, Collazo-Clavell M, Ryu JH. Body mass index and mortality in patients with idiopathic pulmonary fibrosis. Chest. 2007; 131: 1448-1453.

PubMed: https://www.ncbi.nlm.nih.gov/pubmed/17400656

23. Bunn HF, Poyton RO. Oxygen sensing and molecular adaptation to hypoxia. Physiol Rev. 1996; 76: 839-885.

PubMed: https://www.ncbi.nlm.nih.gov/pubmed/8757790

24. Davis PB. Cystic fibrosis since 1938. Am J Respir Crit Care Med. 2006; 173: 475-482.

PubMed: https://www.ncbi.nlm.nih.gov/pubmed/16126935

25. Stark LJ, Powers SW. Behavioral aspects of nutrition in children with cystic fibrosis. Curr Opin Pulm Med. 2005; 11: 539-542.

PubMed: https://www.ncbi.nlm.nih.gov/pubmed/16217182

26. Hsieh MJ, Yang TM, Tsai YH. Nutritional supplementation in patients with chronic obstructive pulmonary disease. J Formos Med Assoc. 2016; 115: 595-601.

PubMed: https://www.ncbi.nlm.nih.gov/pubmed/26822811

27. Königshoff M, Wilhelm A, Jahn A, Sedding D, Amarie OV, et al. The angiotensin II receptor 2 is expressed and mediates angiotensin II signaling in lung fibrosis. Am J Respir Cell Mol Biol. 2007; 37: 640-650. PubMed: https://www.ncbi.nlm.nih.gov/pubmed/17630322

28. Li X, Molina-Molina M, Abdul-Hafez A, Ramirez J, Serrano-Mollar A, et al. Extravascular sources of lung angiotensin peptide synthesis in idiopathic pulmonary fibrosis. Am J Physiol Lung Cell Mol Physiol. 2006; 291: L887-895.

PubMed: https://www.ncbi.nlm.nih.gov/pubmed/16844946

29. Li X, Rayford H, Uhal BD. Essential roles for angiotensin receptor AT1a in bleomycin-induced apoptosis and lung fibrosis in mice. Am J Pathol. 2003; 163: 2523-2530.

PubMed: https://www.ncbi.nlm.nih.gov/pubmed/14633624

30. Meng Y, Meng Y, Li X, Cai SX, Tong WC, et al. [Perindopril and losartan attenuate bleomycin A5-induced pulmonary fibrosis in rats]. Nan Fang Yi Ke Da Xue Xue Bao. 2008; 28: 919-924.

PubMed: https://www.ncbi.nlm.nih.gov/pubmed/18583228

31. Mohammadi-Karakani A1, Ghazi-Khansari M, Sotoudeh M. Lisinopril ameliorates paraquat-induced lung fibrosis. Clin Chim Acta. 2006; 367 : 170-174.

PubMed: https://www.ncbi.nlm.nih.gov/pubmed/16458281

32. Wang R, Ibarra-Sunga $O$, Verlinski $L$, Pick R, Uhal BD. Abrogation of bleomycin-induced epithelial apoptosis and lung fibrosis by captopril or by a caspase inhibitor. Am J Physiol Lung Cell Mol Physiol. 2000; 279: L143-151.

PubMed: https://www.ncbi.nlm.nih.gov/pubmed/10893213

33. Jiang $T$, Tan L, Gao Q, Lu H, Zhu XC, et al. Plasma angiotensin-(1-7) is a potential biomarker for Alzheimer's disease. Curr Neurovasc Res. 2016. PubMed: https://www.ncbi.nlm.nih.gov/pubmed/26907614

34. Etelvino GM, Peluso AA, Santos RA. New components of the reninangiotensin system: alamandine and the MAS-related $\mathrm{G}$ proteincoupled receptor D. Curr Hypertens Rep. 2014; 16: 433.

PubMed: https://www.ncbi.nlm.nih.gov/pubmed/24760442

35. Grobe JL, Mecca AP, Lingis M, Shenoy V, Bolton TA, et al. Prevention of angiotensin II-induced cardiac remodeling by angiotensin-(1-7). Am J Physiol Heart Circ Physiol. 2007; 292: H736-742.

PubMed: https://www.ncbi.nlm.nih.gov/pubmed/17098828 